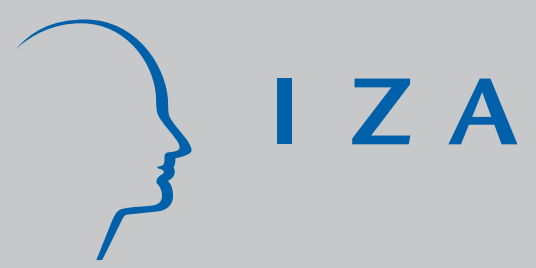

IZA DP No. 3802

The Impacts of Labor Market Policies on J ob Search

Behavior and Post-Unemployment J ob Quality

Simen Gaure

Knut Røed

Lars Westlie

October 2008 


\title{
The Impacts of Labor Market Policies on Job Search Behavior and Post-Unemployment Job Quality
}

\author{
Simen Gaure \\ Ragnar Frisch Centre for Economic Research \\ Knut Røed \\ Ragnar Frisch Centre for Economic Research \\ and IZA \\ Lars Westlie \\ Ragnar Frisch Centre for Economic Research
}

Discussion Paper No. 3802

October 2008

\author{
IZA \\ P.O. Box 7240 \\ 53072 Bonn \\ Germany \\ Phone: +49-228-3894-0 \\ Fax: +49-228-3894-180 \\ E-mail: iza@iza.org
}

\begin{abstract}
Any opinions expressed here are those of the author(s) and not those of IZA. Research published in this series may include views on policy, but the institute itself takes no institutional policy positions.

The Institute for the Study of Labor (IZA) in Bonn is a local and virtual international research center and a place of communication between science, politics and business. IZA is an independent nonprofit organization supported by Deutsche Post World Net. The center is associated with the University of Bonn and offers a stimulating research environment through its international network, workshops and conferences, data service, project support, research visits and doctoral program. IZA engages in (i) original and internationally competitive research in all fields of labor economics, (ii) development of policy concepts, and (iii) dissemination of research results and concepts to the interested public.
\end{abstract}

IZA Discussion Papers often represent preliminary work and are circulated to encourage discussion. Citation of such a paper should account for its provisional character. A revised version may be available directly from the author. 


\begin{abstract}
The Impacts of Labor Market Policies on Job Search Behavior and Post-Unemployment Job Quality

We examine empirically the impacts of labor market policies - in terms of unemployment insurance (UI) and active labor market programs (ALMP) - on the duration and outcome of job search and on the quality of a subsequent job. We find that time invested in job search tends to pay off in the form of higher earnings once a job match is formed. More generous UI raises expected unemployment duration, while improving the quality of the resultant job. Participation in ALMP raises the probability of finding a job and the level of expected earnings, but at the cost of lengthening job search.
\end{abstract}

JEL Classification: C14, C15, C41, J64, J65, J68

Keywords: multivariate hazards, job search, job quality, timing-of-events, NPMLE, MMPH

Corresponding author:

Knut Røed

The Ragnar Frisch Centre for Economic Research

Gaustadalléen 21

0349 Oslo

Norway

E-mail: knut.roed@frisch.uio.no

\footnotetext{
* This research has received financial support from the Norwegian Research Council through the research project "Labor market exclusion", and from the Norwegian ministries of Labor and Social Inclusion and of Finance through the "Strategic Institute Program on Labor Market and Pension Research". It is also part of the research at the ESOP Centre at the Department of Economics, University of Oslo. Thanks to Erik Biørn, Bart Cockx, and Ott Toomet for comments and discussions. Thank also to participants at the ESOP research seminar in Oslo, the Second Joint IZA/IFAU Conference on Labor Market Policy Evaluation in Bonn, and the QMSS research seminar on life course analysis in Oslo.
} 


\section{Introduction}

In this paper, we set up a comprehensive simultaneous equations model accounting for i) the duration and outcome of individual unemployment spells; ii) the subsequent employment stability; and iii) the earnings level associated with the first job after unemployment. The model is designed to examine short- and long-term impacts of external job search conditions as well as of non-random treatment interventions. It is estimated on Norwegian administrative register data covering all new unemployment spells from 1993 to 2001.

It is a well known fact that job search conditions - as reflected in, e.g., unemployment insurance (UI) and active labor market programs (ALMP) - affect the opportunity cost of continued job search, and, hence, a job seeker's fastidiousness and search effort. Participation in ALMP potentially also affects human capital and, hence, the distribution of available job opportunities. A number of empirical studies have examined how these effects play out with respect to the duration and outcome of unemployment spells. Typical findings are that higher UI replacement ratios yield longer unemployment durations, and that the probability of escaping unemployment increases as UI entitlements are exhausted. However, in a recent review of the literature, Card et al. (2007) show that the estimated behavioral responses tend to be much smaller when the spells are measured by the time to next job than when they are measured by the time spent in the UI system. The empirical evidence regarding impacts of UI on job match quality is sparse. Economic theory suggests that UI may encourage job seekers to wait for more productive jobs; see Marimon and Zilibotti (1999) and Acemoglu and Shimer (1999; 2000). If credit markets are imperfect, UI insurance also involves a non-distortionary income (liquidity) effect (in addition to the distortionary substitution effect), reducing the pressure on credit-constrained individuals to accept suboptimal job matches (Chetty, 2008). The relatively sparse existing empirical evidence does not, however, provide any overwhelming evidence that increased UI generosity actually improve job matches. Addison and Blackburn (2000) report evidence of a weak favorable impact of UI on the post-unemployment wage, while Belzil (2001) and Centeno (2004) report evidence of a small favorable impact on job duration. Van Ours and Vodopivec (2008), however, concludes from a "natural experiment” in Slovenia that shortening the duration of UI benefits does not affect either post-unemployment wages or job duration.

The empirical literature on the effects of ALMP is huge, but also somewhat confusing; see Kluve et al. (2007) for a recent overview and meta-analysis. One source of confusion is that ALMP not only affects actual participants, but also potential participants through antici- 
pation or "threat" effects (Black et al., 2003), as well as the population at large through various general equilibrium effects. But even when it comes to the participants' direct causal effects of ALMP, the lack of consensus across studies is conspicuous. One reason for this is that ALMP participation involves a series of (potentially conflicting) impacts - on search effort, fastidiousness, stigma, and human capital - which play out differently over time. For example, we may expect that the job-finding rate declines during the participation period (lock-in effect), while it increases afterwards (post-treatment effect). We may also hypothesize that completed program participation improves human capital and thereby the quality of subsequent job match in terms of earnings and job security. The large variation in reported treatment effects may then simply reflect that different evaluation schemes blend these mechanisms differently.

To our knowledge, no empirical analysis has yet attempted to examine jointly all the direct impacts of UI institutions and ALMP participation on the matching process, in terms of effects on job search duration, on the determination of the ultimate destination state, and on the quality of a resultant job match. A key aim of the present paper is to fill this gap. In addition, we believe that the way we extend the multivariate mixed hazards model to incorporate a simultaneously determined earnings equation represents a methodological novelty.

Based on the timing-of-events approach (Abbring and Van den Berg, 2003), we set up a multivariate hazards model to analyze the transition from unemployment to three alternative destination states: i) employment, ii) ordinary education and iii) inactivity (with health related benefits or social assistance). During the unemployment spell the job seekers are nonrandomly sorted into ALMP. We examine the causal impacts of job search conditions and of actual participation in ALMP on the duration and outcome of job search and on the quality of a resultant job. The latter is measured in terms of monthly earnings and employment duration. In addition to controlling for a rich set of observed explanatory variables, we allow for jointly distributed unobserved heterogeneity by means of the non-parametric maximum likelihood estimator (NPMLE). Our preferred model contains a discretely distributed six-dimensional vector of unobserved heterogeneity with 27 distinct support-points.

The key findings of our paper are the following: First, during its first six months, the job search process is productive in the sense that the expected earnings increase significantly with the time spent searching. On the other hand, the probability of actually obtaining an acceptable job offer declines quite sharply with unemployment duration. And after one year of job search, expected earnings also start to decline. Second, given unemployment duration, weaker activation requirements in the UI system cause reservation wages to increase. As a 
result, it also causes expected unemployment duration to increase and the expected earnings level from an accepted job to rise. Third, reservation wages decline sharply in the run-up to UI exhaustion, causing the job hazard to rise and the expected earnings level to decline in this period. And finally, participation in ALMP initially reduces the employment hazard (lock-in effect), but the impact becomes favorable after around 5-6 months of participation. For most participants and program durations, the employment hazard is also significantly higher after participation than it was before entry into the program. In addition, participation in ALMP tends to improve subsequent earnings. Based on model simulations, we summarize the various treatment effects of actual participation in terms of a comprehensive earnings (value of work) measure, covering a five-year period after the start of unemployment. Even though program participation raises both the probability of eventually finding a job and the level of earnings given that a job is found, it contributes to reduce overall earnings derived from ordinary jobs during the first five years after entry into unemployment. The reason is that it also tends to increase the duration of the overall job search period (including the participation period). Given that ALMP also involves some administrative costs, this implies that it is difficult to defend the programs from a cost-benefit point of view when considering the impacts on subsequent employment performance only. However, many of the program activities (around 60 percent) involve some form of subsidized employment. The condition for a simple five-year cost-benefit analysis to deliver a favorable result is that the economic value of subsidized work is, on average, at least 35 percent of the participants' predicted earnings from non-subsidized work. In addition, activity requirements raise the job finding rate among notyet-participating UI claimants.

The next section presents the data and the institutions from which they are generated. Section 3 describes the empirical methodology and discusses identification, and Section 4 presents the results. Section 5 discusses alternative model specifications and robustness issues, and Section 6 concludes.

\section{Data and institutional background}

The data used in this paper encompass all new entrants into registered unemployment in Norway during the period from October 1993 to September 2001. The term "new" is defined as not having had any unemployment experience during the past three years prior to the first spell in our data window (we use registers back to 1989 to implement this condition for early entrants). We focus on new entrants in this analysis in order to model the complete unem-

ployment history for each individual, realizing that there might be causal linkages between 
subsequent spells and their outcomes. Given that our data window covers 8 years, the delimitation to new entrants does not imply that long-term unemployed and individuals with repeated spells are disregarded. Even the longest unemployment careers have to start at some point, and given that they start during the period spanned by our data, we model the subsequent employment and unemployment experiences until October 2001.

Table 1 offers some key descriptive statistics. There are 373,065 individuals included in our analysis with 413,988 "new" entries into unemployment. Approximately 41,000 individuals (11 percent) have more than one new entry during the 8 year long data-window. In the statistical analysis, multiple new unemployment spells will be treated as causally unrelated. But, as we explain in the next section, they will be related through the assumed persistence of unobserved covariates. In total, around 124,000 individuals (33 percent) experienced more than one unemployment spell. Repeated unemployment spells starting less than three years after the end of a previous spell will be treated as related both through a causal effect (lagged duration dependence) and through the persistence of unobservables.

\begin{tabular}{l|c}
\hline Table 1 & \multicolumn{2}{c}{ The Data - Descriptive statistics corresponding to the time of first entry into unemployment } \\
\hline & 373,065 \\
Number of individuals & 413,988 \\
Number of new unemployment entries 1991.9-2001.9* & 28.22 \\
Mean age at first entry & $4.20(9.03)$ \\
Mean number of years of work experience at first entry (conditional on >0) & 52.25 \\
Percent of entrants female & 9.62 \\
Percent of entrants with immigrant (non-OECD) background & 55.40 \\
Percent with UI at first entry & 66.73 \\
Percent of individuals according to the number of spells in data window & 21.28 \\
One unemployment spell only & 7.50 \\
Two spells & 4.49 \\
Three spells & \\
Four spells or more & \\
\hline
\end{tabular}

* A "new" entry is defined as becoming unemployed after at least three years without any unemployment.

The time period covered by our analysis was characterized by substantial changes in external job search conditions. First, labor demand fluctuated substantially. This is illustrated in the upper panel of Figure 1, where we report a labor market tightness indicator for Norway measuring the time-path of the monthly job transition probability controlled for observed and unobserved individual characteristics, spell duration, and seasonal fluctuations; see Gaure and Røed (2007) for details. Employment prospects improved steadily until the autumn of 1998. During the recovery period from the trough in December 1992 (outside our data window) to the peak in September 1998, a typical job seeker’s monthly probability of finding work doubled, ceteris paribus. From the autumn of 1998, employment prospects again deteriorated. As 
can also be seen from the graph, the cyclical fluctuations embodied in the labor market tightness indicator correlate well with the pattern of new inflows to unemployment observed in our own data. Second, the overall scale of ALMP also changed substantially. This is illustrated in the lower panel of Figure 1, where we show how ALMP intensity - defined as the fraction of long-term unemployed job seekers participating in ALMP - developed over time. The figure clearly indicates that the frequency of ALMP was scaled down during the late 1990's, reflecting new political priorities. Third, in the middle of our data period (January 1997), the Norwegian UI system was reformed. The old UI system offered an initial maximum UI duration of 80 weeks which could be extended by 13 weeks, after which an additional $80(+13)$ week period could be granted at a somewhat reduced benefit level if no employment or suitable ALMP activities could be found; see Røed and Westlie (2007) for details. The new UI system offered an uninterrupted UI period of 156 weeks for most job seekers.
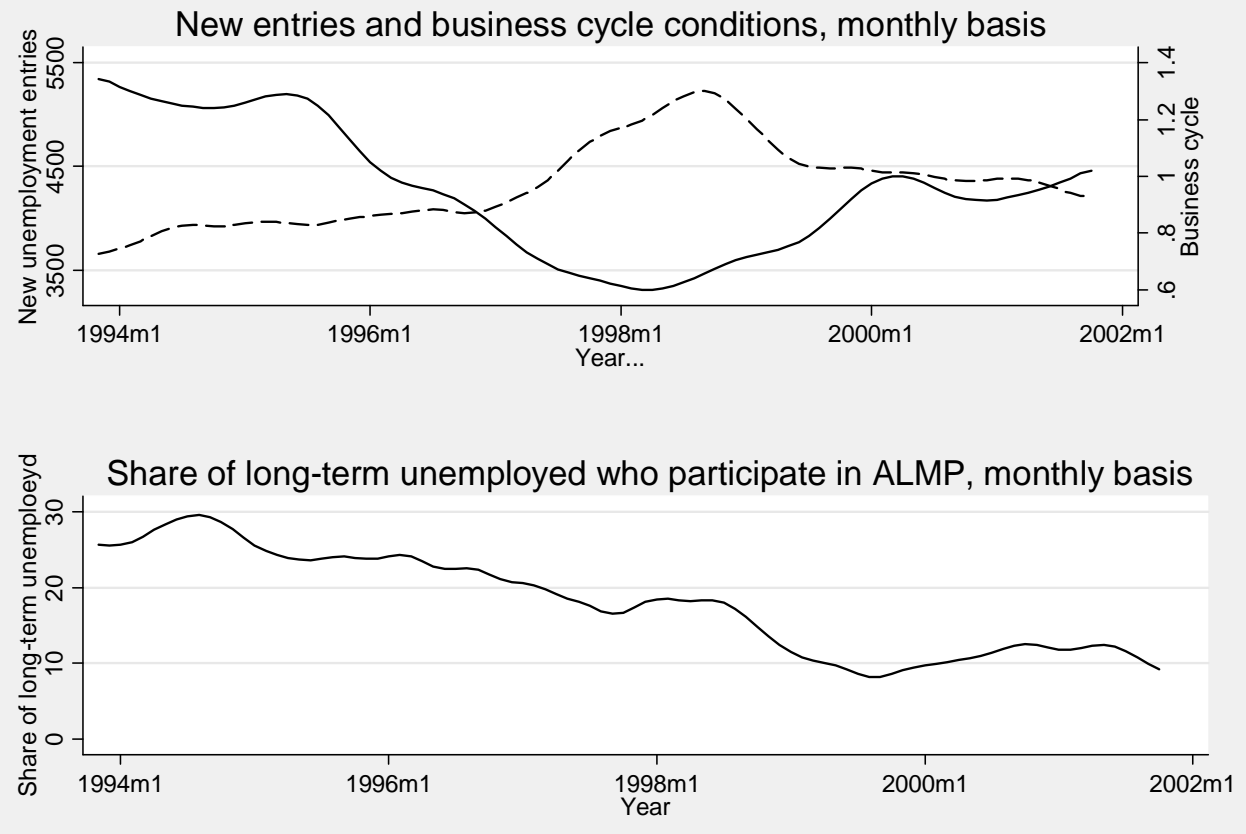

Figure 1. Labor market tightness (dotted line) and the number of new entrants (solid line) to unemployment (upper panel) and the share of long term unemployed participating in labor market programs (lower panel).

Note: The monthly series are smoothed with X11ARIMA. The labor market tightness indicator is collected from Gaure and Røed (2007). It is normalized on June 2000 (representing a "normal" cyclical condition) and can be interpreted as relative changes in the monthly job transition rates over time, conditional on observed and unobserved characteristics and on unemployment spell duration. The lower panel shows the fraction of unemployed with more than six month unemployment duration that participates in ALMP at each point in time.

Note that we do not interpret the 1997 reform primarily as an increase in the overall length of the maximum UI duration. The absolute duration limit was actually higher in the old 
than in the new regime. The main content of the reform was that the UI system changed from focusing on activation to focusing on income insurance and job search. This change in focus largely explains the decline in ALMP participation shown in Figure 1. The reform illustrates an intimate structural relationship between UI design and activation policies in Norway, arising from the dominant view that there exists a lower bound on the income level that can be offered to unemployed job seekers, regardless of their observed search behavior. In practice, this implies that credible UI termination threats can be made only to the extent that paid activation is offered instead. Hence, the reduction in ALMP-intensity and the removal of the "soft" duration constraint after 80 weeks of job search can be viewed as two sides of the same coin.

\section{Methodology}

Starting with the flow of first-time entrants into the state of unemployment, we set up a multivariate mixed semi-proportional hazard rate model (MMSPH), expanded to comprise a loglinear earnings equation for those who get an ordinary job. The model accounts for transitions to employment, to ordinary education, and to social security benefits that do not require continued job search (sickness benefits, rehabilitation benefits, disability benefits or social assistance). During the unemployment spell, transitions to ALMP may occur. ALMP participation is modeled as a non-random event, and it is assumed to induce shifts in all hazard rates, both during the participation period and afterwards. The sizes of the shifts may depend on gender, initial human capital, program duration, and business cycle conditions. All hazard rates are potentially affected by the duration of the ongoing spell, as well as by the duration and outcome of previous spells. All hazards are also affected by UI status (before/after the UI reform) and by the duration of remaining UI entitlements. For individuals who make a transition to employment, it is assumed that the initial earnings level and the subsequent job-loss hazard, depend on the conditions under which the job was accepted (in terms of, e.g., remaining UI entitlements at the time of the job transition) and on previous ALMP participation. All hazard rates as well as earnings are assumed to depend on observed and unobserved characteristics and on calendar time. The various unobserved characteristics (random effects) are allowed to be interrelated in an unrestricted fashion, implying that the parameters of the model are recovered by means of the non-parametric maximum likelihood estimator (NPMLE); see Heckman and Singer (1984) and Gaure et al. (2007). 


\subsection{Model specification}

We set up a multivariate mixed semi-proportional hazard rate model with five events $k=1, \ldots, 5$, together with an earnings equation. The five events are:

1. Termination of the unemployment spell with transition to employment

2. Termination of the unemployment spell with transition to ordinary education

3. Termination of the unemployment spell with transition to other benefit (that does not require continued job search)

4. Entry into ALMP (does not terminate the unemployment spell)

5. Termination of a subsequent employment spell

All the five hazard rates, as well as expected earnings level, are tied together through the joint distribution of unobserved heterogeneity. While we model the entry into ALMP $(k=4)$ as an endogenous event, we treat the potential duration of program participation (in the absence of unemployment termination) as exogenous. This is a questionable strategy. Although the length of each ALMP activity is indeed predetermined, we cannot rule out a systematic (unobserved) sorting process into programs of different durations. This may bias the results regarding the impacts of ALMP duration in an unknown direction (depending on the sorting process into programs of differential durations).

For each transition into ordinary employment $(k=1)$, we also include an earnings equation designed to explain the level of earnings derived from the first full month of employment. Monthly earnings are determined as the product of the hourly wage rate and the number of hours worked. Unfortunately, the data do not provide sufficient information for identifying these two variables separately. Note, however, that all the job seekers included in our analysis have declared interest in a full-time job. High monthly earnings may therefore be viewed as a desirable job characteristic, even when it results from a large number of hours rather than a high hourly wage. Note also that we treat self-employment as a transition to employment. The initial earnings level for self-employed are computed from yearly tax records (based on the assumption that earnings were equally distributed across the non-unemployment months).

When a job spell is terminated $(k=5)$, the worker may return to unemployment, in which case a new unemployment spell is started off. Otherwise, the event history is terminated at this point. ${ }^{1}$ The model is proportional, in the sense that unobserved as well as most

\footnotetext{
${ }^{1}$ Note that it is the length of the employment status that we model. Switches between different jobs are disregarded.
} 
observed covariates are assumed to affect individual hazard rates multiplicatively. However, as we explain below, the model is a generalization of the standard MMPH model, since it allows for interactions of duration dependencies and the impact of some observed explanatory variables. This is why we use the term “semi-proportional” - MMSPH - to describe it.

Table 2 provides a descriptive overview of the events recorded in the data. A key point to note is that only 47 percent of the completed spells end with a transition directly to employment. The remaining transitions are evenly distributed between education, benefit shifting, and other (non-modeled) transitions. The latter include child-birth (for females), military service (for males), self-supported withdrawal from the labor force, emigration, and death. Spells with "other" transition are right-censored. Another important point to note is that employment obtained after a period of unemployment is fragile; 41 percent of the employment spells are terminated within two years of employment, and 43 percent of these employment terminations lead directly back to the unemployment pool. Mean monthly earnings for those who get a job are around 26.000 NOK (3.250 €). The variation is large, however, with a standard deviation around 60 percent.

\begin{tabular}{l|c}
\hline Table 2 & 608,126 \\
Overview of events/outcomes recorded in the data & 94.21 \\
\hline Number of unemployment spells & 5.23 \\
Percent of unemployment spells completed before the end of the observation period & 46.59 \\
Mean duration of completed spells (months) & 16.87 \\
Percent of unemployment spells ending in: & 16.71 \\
Employment & 19.83 \\
Education & 17.12 \\
Other benefit (sickness, rehabilitation, disability, or social assistance) & 41.13 \\
Other (right censored transitions) & 43.03 \\
Percent of completed unemployment spells involving ALMP & 26,292 \\
Percent of employment spells completed within two years & 0.602 \\
Percent of completed employment spells ending in unemployment & \\
Mean monthly earnings from employment in the first months after unemployment (2006 NOK) & \\
\hline
\end{tabular}

Since we observe labor market status by the end of each calendar month only, we set up the statistical model directly in terms of grouped hazard rates (Prentice and Gloeckler, 1978; Meyer, 1990). We write the integrated period-specific hazard rates $\varphi_{\text {kit }}$ as functions of observed (time-varying) variables and unknown parameters represented by index functions $f_{k i t}$, and (time-invariant) unobserved individual characteristics $v_{k i}$ : 


$$
\varphi_{k i t}=\int_{t-1}^{t} \theta_{k i s} d s=\exp \left(f_{k i t}+v_{k i}\right), \quad k=1, \ldots, 5,
$$

where $\theta_{\text {kis }}$ is the underlying continuous-time hazard rate, assumed to be constant within each month. In addition, we specify monthly earnings at the start of the new job as

$$
w_{i t}=\exp \left(f_{6 i t}+v_{6 i}+\varepsilon_{i}\right),
$$

where $f_{6 i t}$ is an index function of observed explanatory variables, $v_{6 i}$ is an unobserved individual characteristic, and $\varepsilon_{i}$ is an error term reflecting genuine randomness in earnings outcomes at the individual level. The latter is assumed to be normally distributed with mean zero and variance $\sigma^{2}$. We write the index functions for the transitions from unemployment as follows:

$$
f_{k i t}=\tau_{k t} s_{i t}+\lambda_{k d t} d_{i t}+\lambda_{k}^{*} \log \left(d_{i t}^{s c a l}\right) c_{i t}+\delta_{k} r_{i t}+\alpha_{k i t} z_{i t}+\beta_{k} x_{i t}, \quad k=1, \ldots, 4,
$$

where $s_{i t}$ is a vector of calendar month dummy variables (one for each calendar month occurring in our data), $d_{i t}$ is a vector of spell duration dummy variables (including a representation of 'lagged' duration from recent previous spells), $d_{i t}^{\text {scal }}$ is a spell duration scalar variable, $c_{i t}$ is a monthly business cycle indicator (see Figure 1, Section 2), $r_{i t}$ is a vector of dummy variables reflecting UI status/regime and the length of remaining UI entitlements, $z_{i t}$ is a vector of dummy variables recording already realized endogenous events (on-going and completed treatment and outcome of previous unemployment spells), and $x_{i t}$ is a vector of individual characteristics (age, education, work-experience, previous income, the level of UI benefits, family status, nationality, and business cycle conditions at the time of first entry). ${ }^{2}$ Note that the effects of endogenous events $\left(\alpha_{k i t}\right)$ vary over individuals as well as time. The reason for this is that we allow the causal effects of ALMP to depend on some key individual characteristics (gender and education), on the duration of ongoing and completed treatment, and on the current business cycle conditions. The impacts of spell duration are to some extent allowed to vary over the business cycle through the interaction of spell duration with business cycle conditions. The parameters associated with the spell duration dummy variables $\left(\lambda_{\text {kdt }}\right)$ reflect duration dependence under "normal” cyclical conditions. A more detailed description of the model (and its variables) will be given as we present the estimation results in the next section.

The index function for the transition from employment is written as:

\footnotetext{
2 The business cycle condition at the time of first entry is included as an individual covariate to capture the potential sorting in the inflow to unemployment over the cycle.
} 


$$
f_{5 i t}=\lambda_{5} \bar{d}_{i}+\delta_{5} \bar{r}_{i}+\lambda_{5}^{*} d_{i t}^{*}+\alpha_{5 i t} \bar{z}_{i}+\psi_{5} \ln \bar{w}_{i}+\tau_{5} c_{t}+\beta_{5} x_{i t},
$$

where $\bar{d}_{i}$ is the duration of the completed job search period, $\bar{r}_{i}$ reflects the remaining UI entitlement at the time of the job transition, $d_{i t}^{*}$ is the duration of the ongoing employment spell, $\bar{Z}_{i}$ is a vector of indicators for realized treatment and part-time work, and $\bar{w}_{i}$ is the the realized level of monthly earnings.

The index function for monthly earnings is written as

$$
f_{6 i t}=\lambda_{6} \bar{d}_{i}+\delta_{6} \bar{r}_{i}+\alpha_{6 i t} \bar{z}_{\boldsymbol{i}}+\tau_{6} c_{t}+\beta_{6} X_{i t},
$$

where $t$ here refers to the month of transition into employment.

A point to note is that all the variables explaining expected acceptable earnings (5) are also assumed to have direct effects on the various hazard rates. Hence, given the unrestricted correlation between unobserved covariates, the level of expected earnings is implicitly included in all the hazard rates.

\subsection{Identification}

Even though we apply a (semi) proportional hazard rate model, we emphasize that nonparametric identification does not rely solely on the proportionality assumption. Additional sources of identification are the existence of repeat spells (Abbring and Van den Berg, 2003) and, more importantly, the abundance of exogenous time-varying covariates (McCall, 1994; Brinch, 2007; Gaure et al., 2007). Of particular value for identification purposes is the substantial calendar time variation in both labor market tightness and in the scale of labor market programs; see Section 2. As pointed out by Eberwein et al. (1997, p. 663), time-varying variables naturally provide an exclusion restriction in the sense that past values of these variables affect the current outcomes only through the already realized selection process. Hence, they facilitate the disentanglement of causal treatment and duration effects from impacts of unobserved sorting. Note that we do not require the calendar time variation in the treatment propensity to be independent of the cyclical variation in, e.g., the employment hazard. Since we include a full set of calendar time dummy variables in all hazard rates, the non-independent variation is fully (non-parametrically) controlled for in the model. The identification of treatment effects also relies on the "no anticipation assumption” (Abbring and Van den Berg, 2003), requiring that individuals do not anticipate the realization of the stochastic process determining treatment events. Since treatments are typically implemented quickly once the relevant decision is made, we view this assumption as defensible. 
Our data make it possible to identify separately the degree of intrinsic duration dependence related to discouragement and/or statistical discrimination and the impact of UI exhaustion. An important source of identification for these parameters is the 1997 UI reform, which introduced an exogenous break in the otherwise strong positive correlation between unemployment duration and UI exhaustion (see Section 2). Participation in ALMP also contributes to the separation of duration and UI exhaustion effects, since many participants do not draw on their UI entitlements while participating in a program activity. Based on two additional assumptions, we can also identify the impacts of the UI reform on the initial hazard rates (before exhaustion effects kick in) and on the subsequent job quality. The first assumption is that non-claimants did not change their behavior as a result of the reform, i.e., that any "eligibility effects” are negligible. Given that the ultimate maximum UI duration was virtually unaffected by the reform, we find this assumption justifiable. The second assumption is that business cycle fluctuations had the same impact on UI claimants (who were affected by the reform) as they had on non-claimants (who presumably were not affected by the reform). Røed and Wes-

tlie (2007) presents empirical evidence indicating that this was indeed the case. However, we cannot entirely rule out that what we will refer to as the "reform effect" also captures other developments that have affected insured and non-insured job-seekers differently.

\subsection{The likelihood function}

Let $K_{i t}$ be the set of feasible events for individual $i$ in month $t$, i.e., $K_{i t}=\{1,2,3,4\}$ when openly unemployed, $K_{i t}=\{1,2,3\}$ when participating in ALMP, and $K_{i t}=\{5\}$ when employed. Let $y_{k i t}, k=1, \ldots, 5$, be an outcome indicator variable, which is equal to 1 if the corresponding observation month ended in a transition to state $k$, and zero otherwise, let $w_{i t}$ be observed initial earnings for individual $i$ who made an employment transition at time $t$, and let $Y_{i}$ be the complete set of outcome indicators available for individual $i$ (potentially collected from multiple spells with multiple earnings observations). The contribution to the likelihood function formed by the event pattern of a particular individual, conditional on the vector of unobserved variables $v_{i}=\left(v_{1 i}, v_{2 i}, v_{3 i}, v_{4 i}, v_{5 i}, v_{6 i}\right)$ can then be formulated as: 


$$
P_{i}\left(v_{i}\right)=\prod_{y_{k i t} \in Y_{i}} \times\left[\begin{array}{l}
\prod_{k \in K_{i t}}\left[\left[\left(1-\exp \left(-\sum_{k \in K_{i t}} \exp \left(f_{k i t}+v_{k i}\right)\right)\right) \frac{\exp \left(f_{k i t}+v_{k i}\right)}{\sum_{k \in K_{i t}} \exp \left(f_{k i t}+v_{k i}\right)}\right]^{y_{k i t}}\right] \\
\left.\left.\times\left[\frac{1}{\sigma \sqrt{2 \pi}} \exp \left(-\frac{\left(\ln w_{i t}-f_{6 i t}-v_{6 i}\right)^{2}}{2 \sigma^{2}}\right)\right]^{y_{1 i t}} \exp \left(f_{k i t}+v_{k i}\right)\right] \sum^{\left.1-\sum_{k \in K_{i t}} y_{k i t}\right)}\right]
\end{array} .\right.
$$

In order to arrive at the marginal likelihood, we need to integrate the six-dimensional vector of unobserved heterogeneity $v_{i}$ out of Equation (6). Standard techniques for doing this rest on the assumption that the unobserved covariates are orthogonal to all other explanatory variables in the model at the time of first entry. However, for interval censored data of the type used here, this assumption is violated. The reason for this is that the interval censoring creates a left-truncation problem, i.e., some individuals with only very short spells - those starting and ending in the same month - are never recorded. Consequently, we have a selected sample, in which unobserved heterogeneity cannot be assumed independent of either observed covariates or calendar time, since the impact of unobserved heterogeneity during the first (censored) month depends on the values of all other explanatory variables. The solution to this problem is to set up the likelihood function conditional on the first spell surviving to the first observation point, and use Bayes' theorem to derive the appropriate distribution of unobserved heterogeneity. We assume that the entrances to the origin state are uniformly distributed within each calendar month. Let $\bar{t}_{1 i}$ be the first inflow month of the first spell for individual $i$. The probability of surviving the inflow month - i.e., of being included in the analysis population - is then equal to

$$
S_{i}\left(v_{i}\right)=\frac{1-\exp \left(-\sum_{k \in K_{\bar{t}_{i} i}} \exp \left(f_{k i \bar{t}_{i i}}+v_{k i}\right)\right)}{\sum_{k \in K_{i \overline{T_{i}}}} \exp \left(f_{k i \bar{t}_{1 i}}+v_{k i}\right)} .
$$

If $f\left(v_{i}\right)$ denotes the unconditional heterogeneity density function (at the time of first entry into unemployment) it follows from Bayes’ theorem that 


$$
f\left(v_{i} \mid \text { survival of entry month }\right)=\frac{S_{i}\left(v_{i}\right)}{E\left[S_{i}\left(v_{i}\right)\right]} f\left(v_{i}\right) .
$$

To ensure that our estimation results to the largest possible extent are driven by the data and not by unjustified restrictions on the heterogeneity distribution, we introduce unobserved heterogeneity non-parametrically by means of the non-parametric maximumlikelihood estimator (NPMLE). In practice, this implies that the vectors of unobserved attributes are jointly discretely distributed (Lindsay, 1983) with the number of mass-points chosen by adding location vectors until it is no longer possible to increase the likelihood function (Heckman and Singer, 1984). Assuming that the unobserved covariates are jointly discretely distributed with Q number of support points, we can write the data likelihood function as

$$
L=\prod_{i=1}^{N} \frac{\sum_{l=1}^{Q} q_{l}\left(P_{i}\left(v_{l}\right) S_{i}\left(v_{l}\right)\right)}{\sum_{l=1}^{Q} q_{l} S_{i}\left(v_{l}\right)}, \quad \sum_{l=1}^{Q} q_{l}=1
$$

where $\left\{v_{l}, q_{l}\right\}, l=1,2, \ldots Q$, are the location vectors and probabilities characterizing the heterogeneity distribution, and the functions $P_{i}(),. S_{i}($.$) are defined in (6) and (7), respectively.$ We use the optimization algorithm described in Gaure et al. (2007).

\section{Main Results}

Our model contains around 1,700 estimated parameters. Most of them are included solely for control purposes and are unimportant for the topics discussed in this paper. Hence, we do not present the results in any detail. A complete list of estimation results is posted on our website www.frisch.uio.no/docs/job_search.html. Some alternative models and robustness checks are provided in the next section. In this section, we focus on key results related to duration dependence, UI institutions and activation requirements, ALMP treatment effects, and other results of economic interest. The results are presented in terms of individual parameter estimates (relative hazard rates) and full simulation exercises. We present the results from the preferred model, which was selected on the basis of the Akaike information criterion (AIC); see Gaure et al. (2007) for a justification of this choice. This model required 27 support points in the heterogeneity distribution. The results are highly robust to the exact number of support points, however, at least as long as the number lies somewhere between 15 and 35; see Section 5.4. 


\subsection{Duration dependence and the impact of past unemployment}

We start out presenting the so-called baseline hazards for the four events potentially occurring during job search; see Figure 2. The graphs are normalized to unity for the first duration month and display the degrees of duration dependencies during a first unemployment spell under "normal” (average) business cycle conditions. The baseline hazards are computed net of any direct UI exhaustion effects, i.e., they are drawn "as if" potential UI duration is openended (see next subsection). There is clearly negative duration dependence in the employment, education, and ALMP participation hazards. ${ }^{3}$ The other-benefit-hazard is relatively stable, with weak negative duration dependence initially, followed by positive duration dependence. Our model also includes an interaction term between spell duration and a monthly labor market tightness indicator (see Section 2). We find that the degree of negative duration dependence in the job hazard is stronger the tighter the labor market (not shown), indicating that stigma associated with long-term unemployment is triggered faster in good times than in bad times. Moving from the worst observed to the best observed cyclical conditions implies that the job hazard rate of a long-term unemployed (12 months) relative to that of a new entrant declines by around 3.5 percent, ceteris paribus. ${ }^{4}$

Job search duration also affects the expected quality of the job match. Figure 3 displays the estimated impacts of job search duration on subsequent earnings and employment stability. A key finding is that a longer job search period pays off in terms of higher expected earnings once a job is obtained. This is consistent with the notion that job search is a productive endeavor. However, there is no additional earnings gain associated with job search beyond approximately 6 months, and after 15 months the impact of lengthening the search period becomes negative. The latter finding may reflect human capital depreciation, statistical discrimination against long-term unemployment, or a reduction in reservation wages arising from learning (more realistic assessment of earnings options) or from liquidity constraints. It is also worth noting that longer job search periods do apparently not result in safer jobs.

\footnotetext{
${ }^{3}$ Note that the large drop in the education hazard after a few months of job search most likely arises from students seeking work during their summer breaks.

${ }^{4}$ Unemployment experiences from previous spells are also allowed to causally affect the hazard rates out of unemployment provided that they were completed less than three years prior to the start of the ongoing spell (otherwise they are linked to the current spell only through the common vector of unobserved covariates). The impact of unemployment experience from previous spells on current hazard rates depend on the outcome of those spells. We do not report these results here, except noting that past short unemployment spells (less than 12 months) with successful outcomes (in the sense that they ended with a job) have negligible effects on the outcome of subsequent spells. Longer previous spells, and spells without a successful outcome, have more adverse effects on the outcome of subsequent spells, particularly if the spells are close in time.
} 

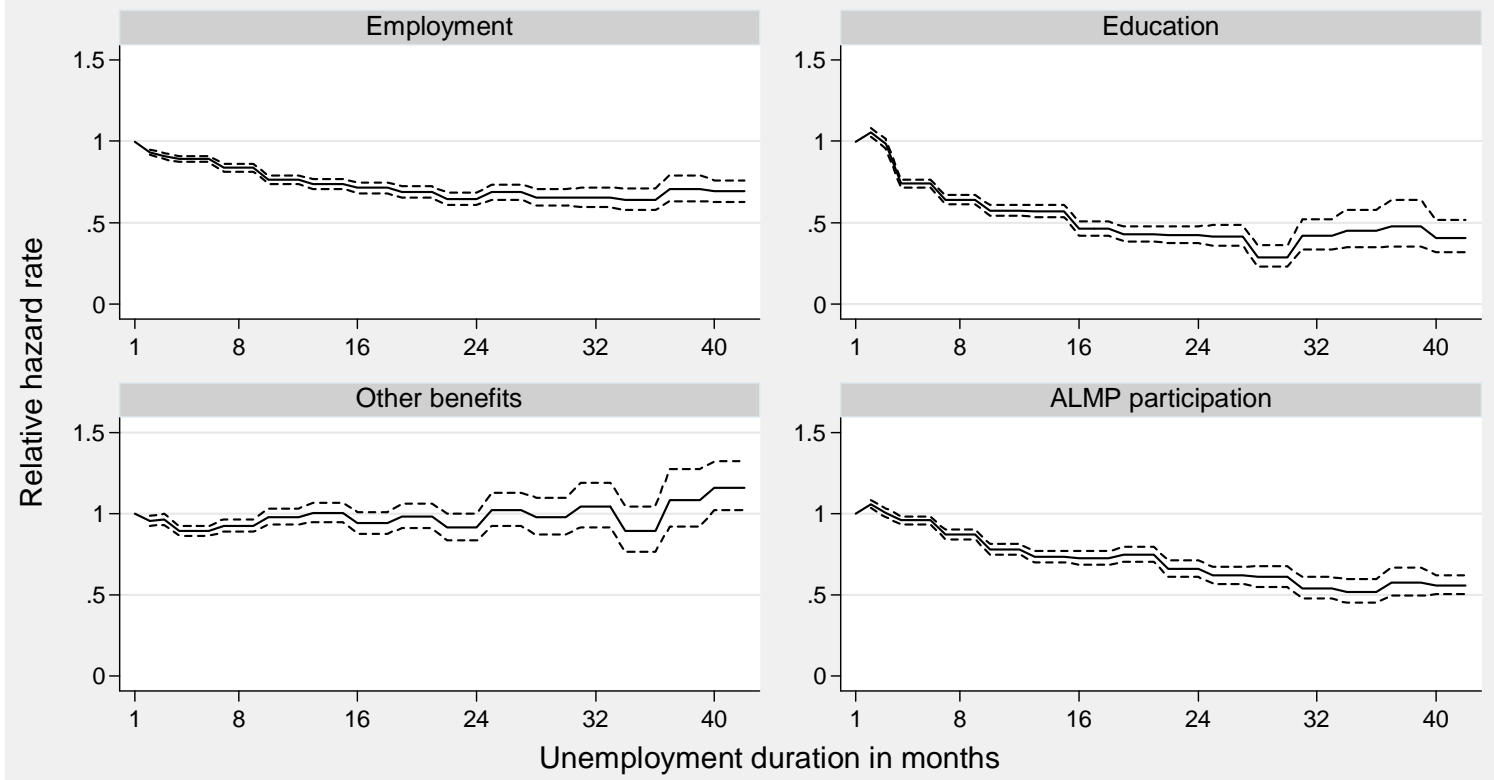

Figure 2. The estimated unemployment duration effects on the hazard rates out of unemployment, with 95 percent confidence intervals.

Note: All effects are normalized on the first month and reflect relative changes in hazard rates as duration increases, ceteris paribus. The reported duration effects in panels 1-5 apply for a new entrant to unemployment (with no previous unemployment during the last three years) under "normal” business cycle conditions.
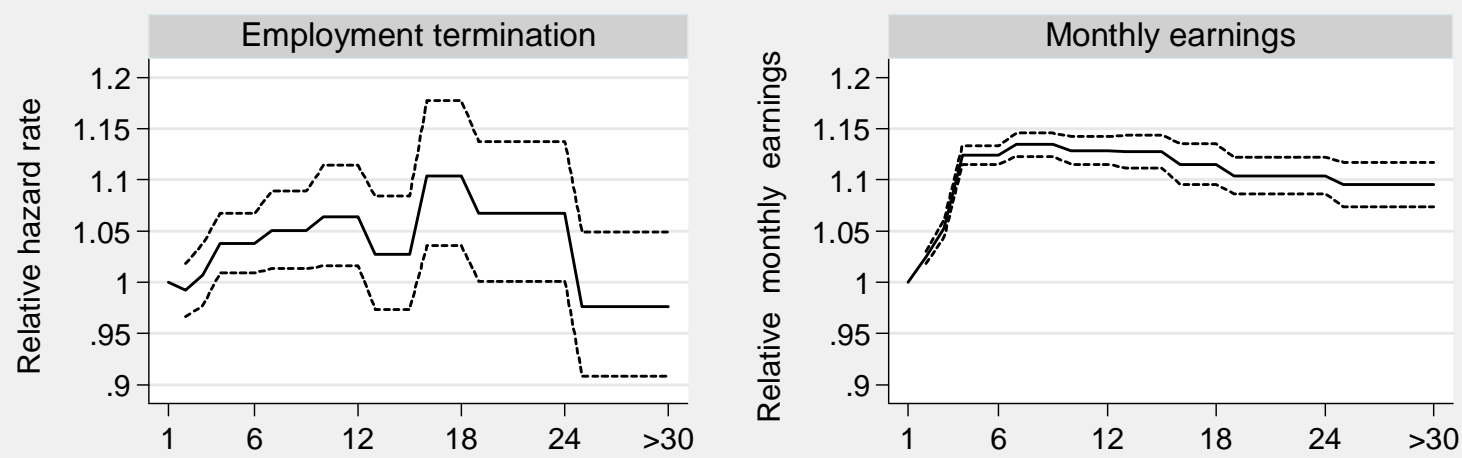

Completed unemployment duration in months

Figure 3. The impact of completed unemployment duration on earnings and employment stability, with 95 percent confidence interval

Job security improves rapidly with tenure. This is illustrated in Figure 4, where we display the estimated baseline hazard for the termination of jobs found after unemployed job search (note that we now measure employment duration, and not unemployment duration, on 
the horizontal axis). The monthly probability of ending a newly obtained employment status declines by around 70 percent during the first year of employment.

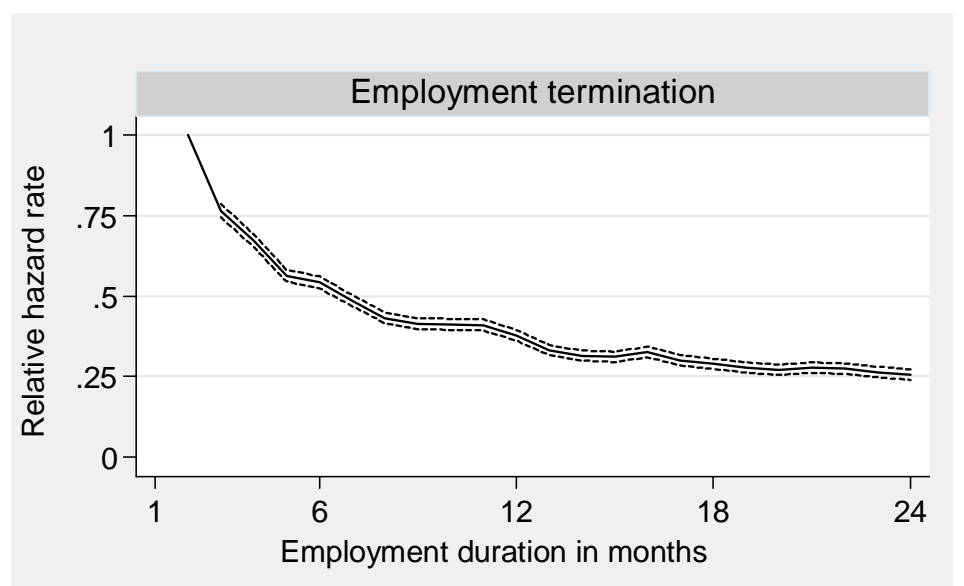

Figure 4. The estimated employment duration effect on the hazard rate out of employment, with 95 percent confidence intervals.

Note: The effect is normalized on the first month and reflect relative changes in hazard rates as employment duration increases, ceteris paribus.

\subsection{The impacts of the UI system}

The UI system is represented in the model by UI regime dummy variables (see Section 2) and by a vector of dummy variables “counting down” to UI exhaustion during the six months just prior to benefit termination. ${ }^{5}$

The effects of UI regime are presented in Tables 3 and 4. Compared with entrants belonging to the pre-1997 UI system, non-eligible entrants have lower employment and education hazards and a higher sickness/disability hazard. It is also worth noting that non-eligible job searchers tend to accept around 9 percent lower earnings than eligible job searchers, ceteris paribus. These effects must be interpreted with care since UI eligibility is not assigned randomly. ${ }^{6}$ However, the causal impacts of the 1997 reform are identified, provided that the reform did not affect the behavior of the non-eligible and that economic fluctuations affected eligible and non-eligible job seekers in a similar fashion; see Section 3. The results reported in

\footnotetext{
${ }^{5}$ We also include a dummy indicating close contact between job searcher and case worker. This dummy is equal to one during UI application periods. An application period occurs when an eligible individual starts a new unemployment spell, unless he/she continues to draw on existing UI entitlements (if a previous spell was concluded less than 12 months ago). An application period also occurs after exhaustion of the initial 80 week period in the pre-1997 UI system; see Røed and Westlie (2007) for details. Application periods entail a relatively close contact with the employment office, including the sorting out of potential job opportunities.

${ }^{6}$ UI eligibility requires that yearly labor earnings exceeded approximately 60,000 NOK in the year prior to the start of the unemployment spell (or that the average income during the past three years exceeded that amount).
} 
Table 3 indicate that the reform caused negative shifts in all hazard rates out of unemployment. Other things equal, the employment hazard fell by around 17 percent $(100 \times(1$-exp(0.188)). It is also clear from Table 4 that the transition to a less activation oriented regime caused an improvement in the quality of accepted jobs, conditional on unemployment duration. Earnings increased by around 5 percent, while the subsequent employment termination hazard declined by 3 percent.

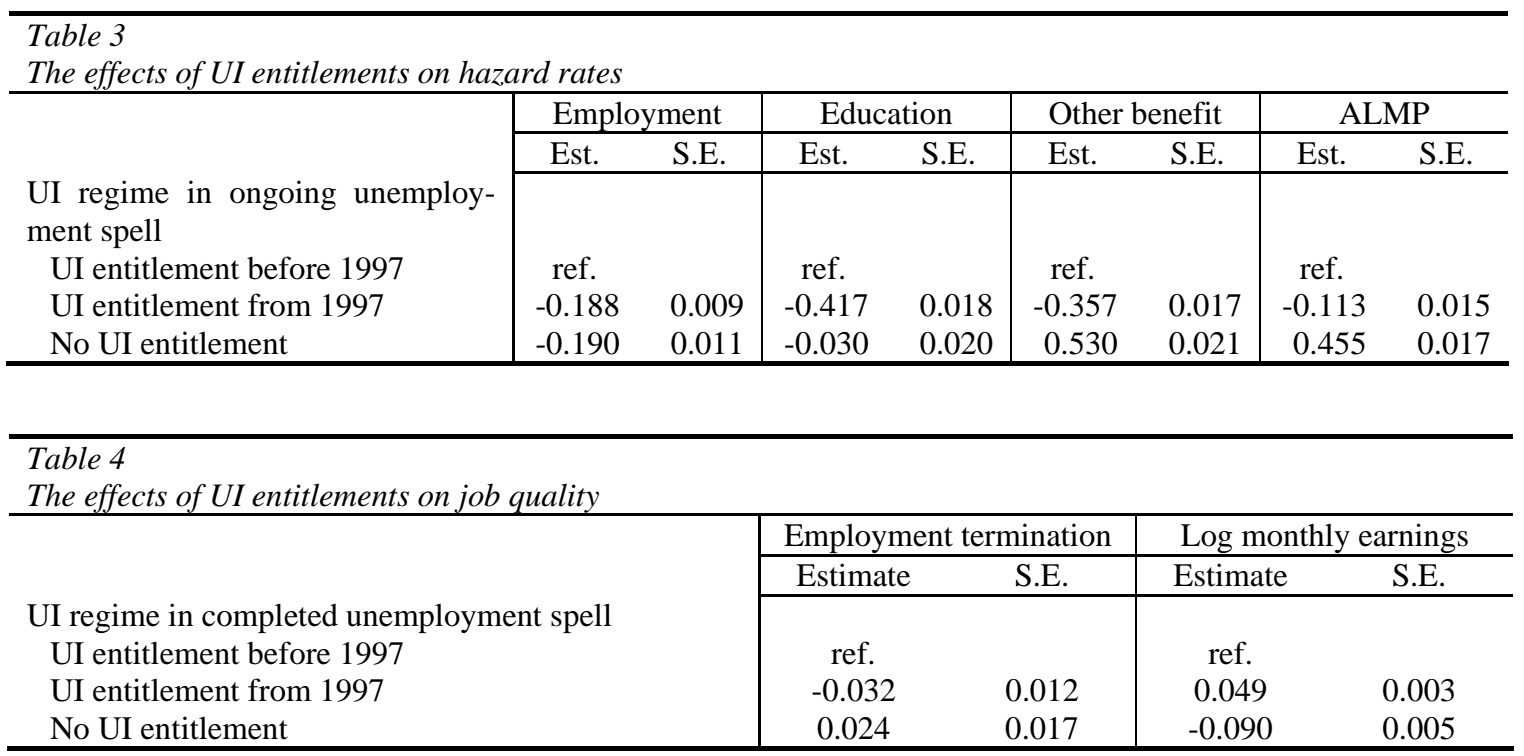

Figure 5 displays the estimated shape of the hazard rates in the run-up to UI exhaustion, relative to claimants with more than six months left of their UI period. Unsurprisingly, all hazard rates rise significantly as the moment of benefit exhaustion approaches. In addition both employment and education hazards remain at a relatively high level after exhaustion. An explanation for the drop in the hazards to other benefits and ALMP may be that those who remain unemployed after UI exhaustion also to a large extent have exhausted their options in terms of other benefits and ALMP offers.

Exhaustion of UI benefits also affects fastidiousness and reservation wages; see Figure 6. We find that realized earnings are significantly lower for jobs accepted in the run-up to UI exhaustion than for jobs accepted earlier in the unemployment spell. For jobs accepted during the last two months of the UI period, the earnings loss (compared to a situation with more than six months left) is close to 10 percent. This indicates that the reservation wage indeed declines significantly as UI entitlements are exhausted. However, jobs accepted after UI exhaustion are again associated with somewhat higher earnings and employment stability than jobs accepted in the run-up to exhaustion. A possible interpretation of this finding is that the impact of UI exhaustion on the reservation wage is really heterogeneous across individuals (in 
contrast to the model's assumption of a homogeneous effect), and that individuals with the largest responses are sorted out of unemployment during the exhaustion period.

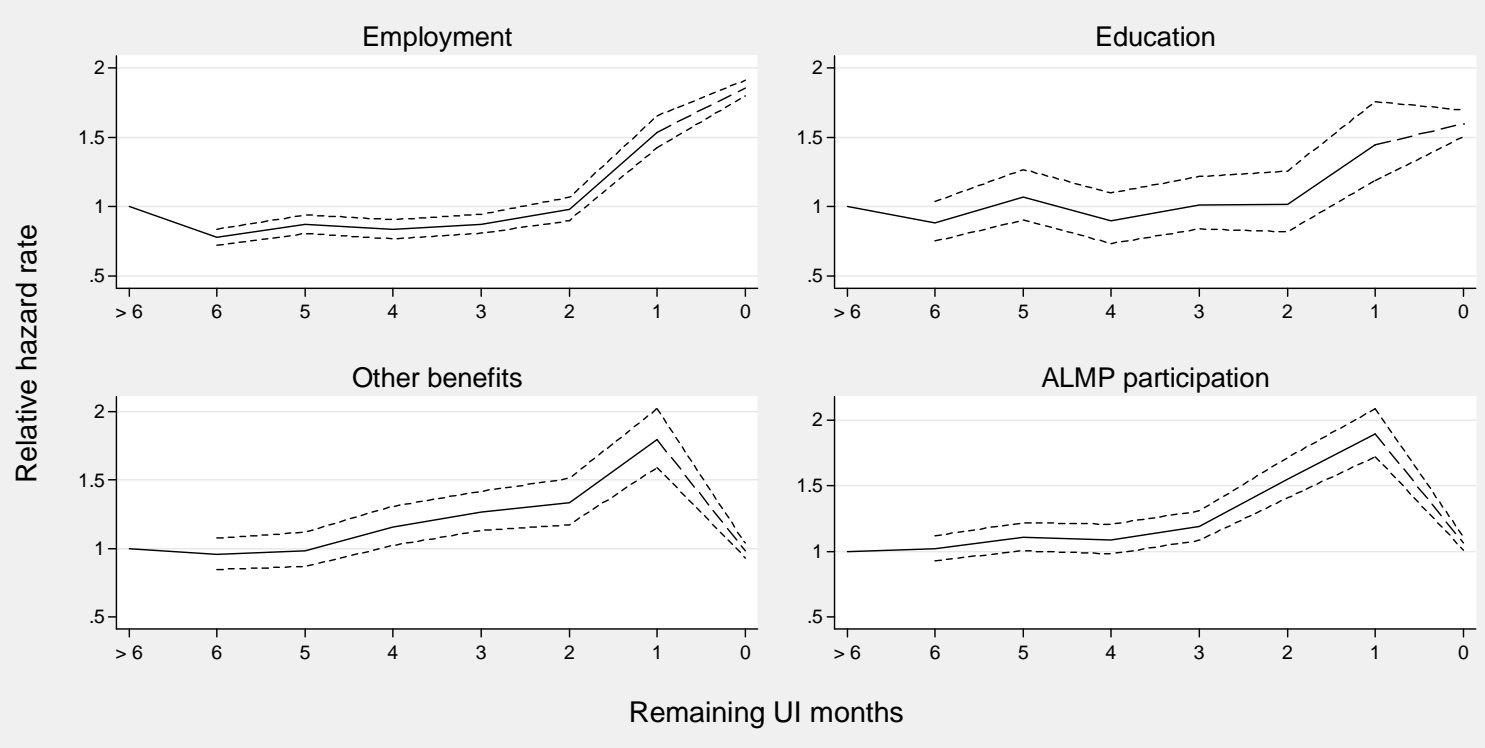

Figure 5. The impacts of UI exhaustion on hazard rates out of open unemployment, with 95 percent confidence intervals

Note: The graphs are normalized on a situation with more than six months left of the UI period.

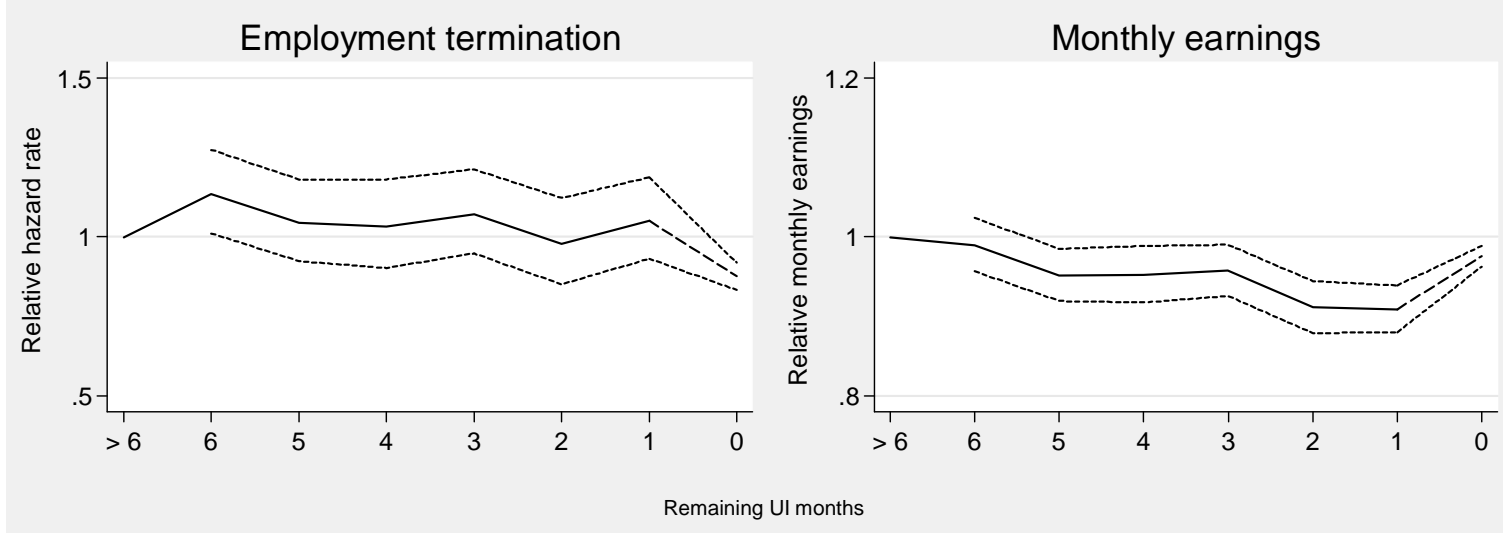

Figure 6. The impacts of UI exhaustion on the expected quality of the accepted job, with 95 percent confidence intervals

Note: The graphs are normalized on a situation with more than six months left of the UI period.

In order to summarize the impacts of the 1997 UI-reform, we perform a simulation exercise; i.e., we use the estimated model to simulate the outcomes (in terms of unemployment duration, destination state, and - if the destination state is employment - earnings and employment duration) of all insured unemployment spells under the old and the new regime, ceteris paribus. We restrict attention to the outcomes of each individual's first unemployment spell, since repeat spells are only partly modeled. In the simulation exercises, we keep business cycles and other time-varying covariates constant (at their mean levels), implying that we can eliminate the right-censoring problem present in the real data (we follow all spells for up 
to five years, even if they stretch beyond our data window). The pre and post reform simulations are different only with respect to the value of the appropriate regime variables, except that the calendar time effects in the treatment hazard are scaled such that they are equal to their estimated pre and post reform averages, respectively, implying that the treatment hazard is approximately 30 percent higher in the pre than in the post reform regime, ceteris paribus. In order to obtain confidence intervals for our simulation results, we use a parametric bootstrap procedure, i.e., we draw parameter estimates repeatedly from their joint normal distribution. $^{7}$ In total, we make 120 simulations under each regime, and calculate 95 percent confidence intervals for the statistics of interest.

Table 5

Simulated impacts of the 1997 UI reform

\begin{tabular}{|c|c|c|c|}
\hline & I & II & III \\
\hline & $\begin{array}{l}\text { Based on the pre- } \\
1997 \text { system. All } \\
\text { unemployed are } \\
\text { entitled to } 2 * 80 \\
\text { weeks of UI- } \\
\text { insurance }\end{array}$ & $\begin{array}{l}\text { Based on the af- } \\
\text { ter-1997 system. } \\
\text { All unemployed } \\
\text { are entitled to } 156 \\
\text { weeks of UI- } \\
\text { insurance }\end{array}$ & $\begin{array}{c}\text { Difference } \\
\text { (II-I) } \\
\text { [95\% CI in } \\
\text { brackets] }\end{array}$ \\
\hline \multicolumn{4}{|l|}{$\begin{array}{l}\text { Outcomes of the first unemployment spell } \\
\text { Percent of unemployment spells ending in }\end{array}$} \\
\hline Employment & 69.53 & 72.22 & $\begin{array}{c}2.69 \\
{[2.01,3.35]}\end{array}$ \\
\hline Education & 14.63 & 12.81 & $\begin{array}{c}-1.82 \\
{[-2.20,-1.34]}\end{array}$ \\
\hline Other benefit & 15.15 & 13.81 & $\begin{array}{c}-1.34 \\
{[-1.82,-0.69]}\end{array}$ \\
\hline Censored due to end of observation period & 0.68 & 1.16 & $\begin{array}{c}0.47 \\
{[0.35,0.60]}\end{array}$ \\
\hline Mean duration of unemployment spells (months) & 6.61 & 8.41 & $\begin{array}{c}1.80 \\
{[1.65,1.97]}\end{array}$ \\
\hline Outcomes of the first employment spell & & & \\
\hline Mean monthly earnings first employment spell & 30,813 & 32,132 & $\begin{array}{c}1,319 \\
{[1086,1510]}\end{array}$ \\
\hline $\begin{array}{l}\text { Fraction of employment spells terminated within } \\
\text { first year after employment transition }\end{array}$ & 27.09 & 27.22 & $\begin{array}{c}0.13 \\
{[-0.75,0.56]}\end{array}$ \\
\hline
\end{tabular}

The results are provided in Table 5. They show that the reform (the introduction of a single uninterrupted 3-year UI period with limited activity requirements) caused mean unemployment duration to increase by 1.8 months (around 27 percent). The rise in unemployment duration was accompanied by an increase in the proportion of unemployment spells ending

\footnotetext{
${ }^{7}$ We draw parameters attached to observed explanatory variables only, since heterogeneity parameters are not normally distributed; see Gaure et al. (2007). The drawings of parameter estimates are made by means of the Cholesky decomposition; i.e., let $L$ be a lower triangular matrix, such that the estimated covariance matrix is $V=L L^{\prime}$. Let $z_{s}$ be a vector of drawings from the standard normal distribution collected for trial $s$. Let $\hat{b}$ be the vector of point-estimates. The parameters drawn for trial $s$ are then given as $b_{s}=\hat{b}+L z_{s}$.
} 
with a transition to employment (by 2.7 percentage points). In line with the findings reported in Table 4, we also find that realized first-job-earnings increased by around 4.3 percent as a result of the reform.

\subsection{The impacts of ALMP}

The estimated direct impacts of ALMP participation on events during the job search period are presented in Table 6. For both on-program and post-program effects we first report the estimated effects for a reference individual (defined at the bottom of the table). The associated relative shift in the hazard rates due to program participation is obtained by taking the exponential function of these numbers. For each combination of explanatory variables, the ALMP effects on the hazard rates can be computed as the appropriate product of variables and parameter estimates reported in the subsequent rows.

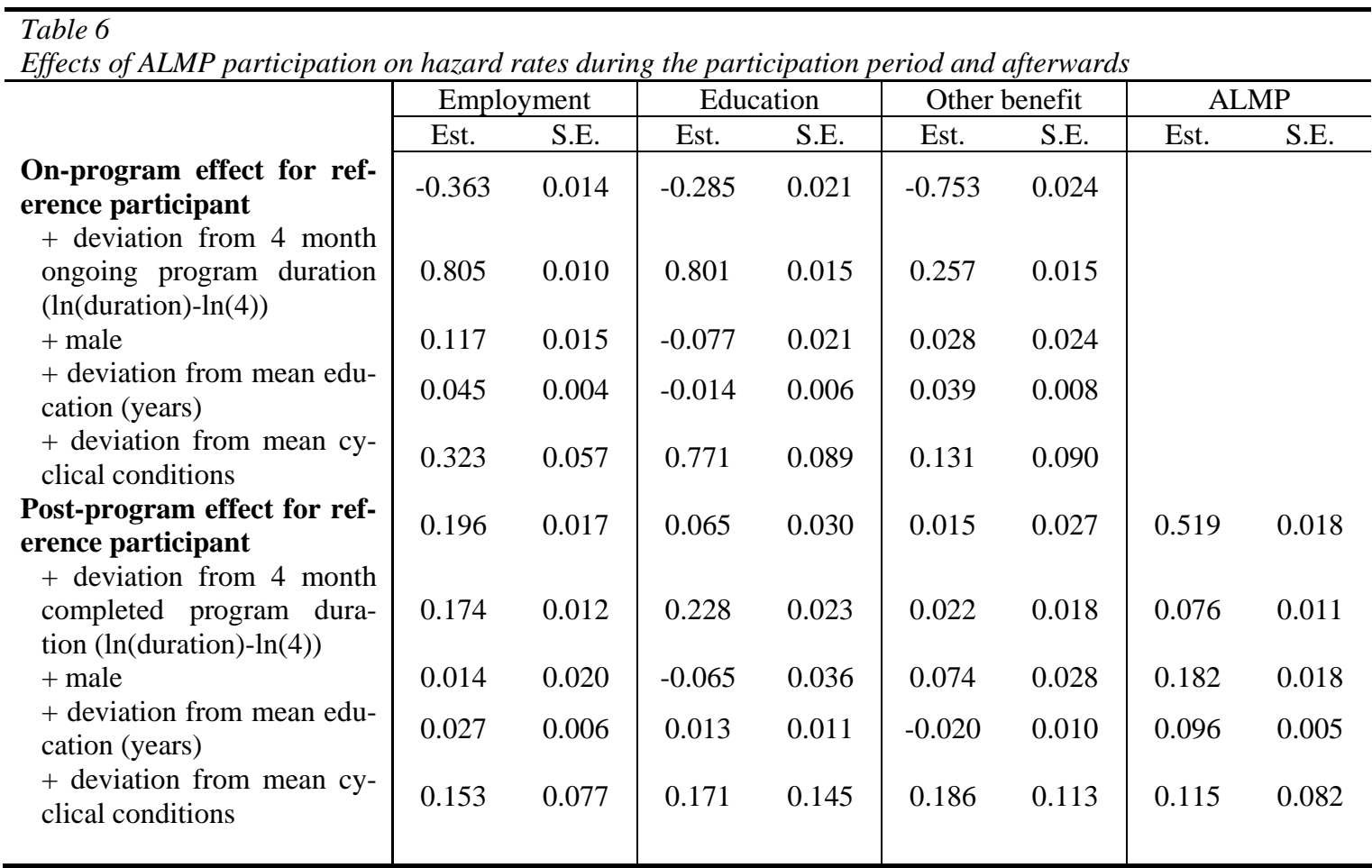

Reference: female participant, 4 months program duration, 12 years education, and “normal” business cycle conditions.

A key finding is that ALMP participation reduces the employment hazard sharply during the initial stages of participation (lock-in effect), but that the effect gradually becomes less negative as the treatment is continued. For a typical participant, the employment effect becomes positive after 5-6 months of participation. ALMP also raises the employment hazard after completion of the program, compared to the pre-participation period (post-program effect). A general finding is that the favorable effects of ALMP are largest for men and for per- 
sons with high education. The effects are also more favorable in a tight than in a slack labor market. The finding of a more favorable treatment effect the higher the educational attainment contrasts with the previously reported negative interaction effect reported by Røed and Raaum (2006). However, their analysis was limited to insured unemployment spells, and all exits from unemployment were aggregated into a single destination state.

Participation in ALMP also potentially affects the quality of a subsequent job; see Table 7. We find that very short ALMP's tend to have a negative impact on both earnings and job stability. For a typical worker, the earnings effect varies from minus five percent for very short programs (one month) to plus 10 percent for long programs (nine months). Longer programs also tend to improve job stability, with a reduction in the job termination hazard of around five percent, ceteris paribus. As discussed in Section 3.1, we cannot rule out that differential results by treatment duration reflect sorting into programs of different lengths.

\begin{tabular}{|c|c|c|c|c|}
\hline \multicolumn{5}{|c|}{$\begin{array}{l}\text { Table } 7 \\
\text { Effects of ALMP participation on the quality of a realized job }\end{array}$} \\
\hline \multirow{7}{*}{$\begin{array}{l}\text { Effect of program reference } \\
\text { + completed program duration (ln(duration)-ln(4)) } \\
\text { + male } \\
\text { + deviation from mean education (years) } \\
\text { + deviation from mean cyclical conditions }\end{array}$} & \multicolumn{2}{|c|}{ Employment termination } & \multicolumn{2}{|c|}{ Log monthly earnings } \\
\hline & Estimate & S.E. & Estimate & S.E. \\
\hline & 0.051 & 0.019 & 0.040 & 0.005 \\
\hline & -0.138 & 0.012 & 0.070 & 0.003 \\
\hline & -0.074 & 0.019 & -0.019 & 0.005 \\
\hline & -0.016 & 0.006 & 0.006 & 0.001 \\
\hline & -0.025 & 0.068 & 0.030 & 0.022 \\
\hline
\end{tabular}

Reference: female participant, 4 months program duration, 12 years education, and "normal” business cycle conditions.

In order to evaluate the overall impact of ALMP, we perform a simulation exercise similar to the one described in the previous subsection, only this time we manipulate the impacts of ALMP. More specifically, we compare simulations based on the estimated model with simulations based on the same estimated model, with the important exception that ALMP is assumed irrelevant (the impacts on all final destination hazards are set to zero). The latter simulations represent the no-treatment-world, with the important qualification that it does not remove the effects that a given program structure may have on search behavior other than through actual participation. Note, however, that the group of participants is identified even in the no-treatment world, based on exactly the same sorting process as in the treatment world (the only difference is that treatment is completely irrelevant in the non-treatment world). This implies that we can compare the group of treated individuals with and without actual treatment. It also implies that we can characterize the sorting process into treatment. 


\begin{tabular}{|c|c|c|c|c|}
\hline \multicolumn{5}{|l|}{$\begin{array}{l}\text { Table } 8 \\
\text { Overall effects of ALMP participation }\end{array}$} \\
\hline & $I$ & II & III & $I V$ \\
\hline & $\begin{array}{l}\text { Non- } \\
\text { participants }\end{array}$ & $\begin{array}{l}\text { Participants } \\
\text { without } \\
\text { ALMP }\end{array}$ & $\begin{array}{l}\text { Participants } \\
\text { with ALMP }\end{array}$ & $\begin{array}{c}\text { Effect of } \\
\text { ALMP } \\
(I I I-I I) \\
\text { [95\% CI in } \\
\text { brackets] }\end{array}$ \\
\hline \multicolumn{5}{|l|}{ Outcomes of the first unemployment spell } \\
\hline $\begin{array}{l}\text { Percent of unemployment spells ending in } \\
\text { Employment }\end{array}$ & 55.69 & 47.25 & 49.32 & $\begin{array}{c}2.07 \\
{[1.46,2.79]}\end{array}$ \\
\hline Education & 25.72 & 25.10 & 23.52 & $\begin{array}{c}-1.58 \\
{[-2.15,-0.93]}\end{array}$ \\
\hline Other benefit & 18.16 & 25.03 & 24.98 & $\begin{array}{c}-0.05 \\
{[-0.70,0.60]}\end{array}$ \\
\hline Censored due to end of observation period & 0.42 & 2.62 & 2.18 & $\begin{array}{c}-0.43 \\
{[-0.63,-0.25]}\end{array}$ \\
\hline Mean duration of unemployment spells & 5.19 & 13.95 & 15.18 & $\begin{array}{c}1.23 \\
{[1.04,1.41]}\end{array}$ \\
\hline Share of population & 84.31 & 15.69 & 15.69 & $\begin{array}{l}0.00 \\
{[-0.16,0.19]}\end{array}$ \\
\hline Outcomes of the first employment spell & & & & \\
\hline $\begin{array}{l}\text { Mean monthly earnings first employment } \\
\text { spell }\end{array}$ & 27,967 & 25,265 & 25,908 & $\begin{array}{c}642 \\
{[288,1,043]}\end{array}$ \\
\hline $\begin{array}{l}\text { Percent of employment spells terminated } \\
\text { within first year after employment transition } \\
\text { Overall earnings and costs first five years } \\
\text { after entry into unemployment }\end{array}$ & 29.63 & 35.12 & 36.54 & $\begin{array}{c}1.42 \\
{[0.40,2.58]}\end{array}$ \\
\hline $\begin{array}{l}\text { A. Total mean earnings generated per partici- } \\
\text { pant in ordinary (non-subsidized) jobs }\end{array}$ & $1,056,245$ & 700,667 & 689,739 & $\begin{array}{c}-10,928 \\
{[-20,851,371]}\end{array}$ \\
\hline Share of population & 73.45 & 26.55 & 26.55 & $\begin{array}{c}0.00 \\
{[-0.20,0.18]}\end{array}$ \\
\hline $\begin{array}{l}\text { Mean number of months in ALMP per par- } \\
\text { ticipant }\end{array}$ & - & - & 5.73 & \\
\hline $\begin{array}{l}\text { Mean number of months in unemployment } \\
\text { (including ALMP participation) }\end{array}$ & 9.85 & 19.33 & 20.47 & $\begin{array}{c}1.14 \\
{[0.99,1.23]}\end{array}$ \\
\hline $\begin{array}{l}\text { Mean number of months in ordinary em- } \\
\text { ployment }\end{array}$ & 38.39 & 27.72 & 26.73 & $\begin{array}{c}-0.99 \\
{[-1.21,-0.71]}\end{array}$ \\
\hline $\begin{array}{l}\text { B. Total mean economic value generated } \\
\text { through program participation (subsidized } \\
\text { jobs) per participant }\end{array}$ & & 0 & 45,130 & 45,130 \\
\hline $\begin{array}{l}\text { C. Total mean operating cost of ALMP per } \\
\text { participant }\end{array}$ & & 0 & 21,086 & 21,086 \\
\hline D. ALMP net surplus per participant $(\mathrm{A}+\mathrm{B}-\mathrm{C})$ & & & & $\begin{array}{c}13,116 \\
{[3,193,24,415]} \\
\end{array}$ \\
\hline
\end{tabular}

Note: Sum earnings are calculated on the basis of the assumption that the earnings levels remain constant within employment spell. Effect measures per participant (Column III) are calculated by dividing the difference between the ALMP and the non-ALMP worlds on the fraction of actual participants in the world with ALMP. Outcomes for ALMP participants in the non-ALMP world are computed by subtracting the effect (Column III) from the outcome with ALMP (Column I).

The results are provided in Table 8. The first two columns summarize the outcomes for non-participants and participants in the absence of any treatment effects. The results indicate that there is a negative selection into ALMP. The likelihood of ending up in employment is on average 8.4 percentage points higher for non-participants than for participants, and their 
earnings are around 11 percent higher, given that they do find a job. Non-participants' unemployment spells are also on average almost 9 months shorter than those of participants, but this primarily reflects that the participation probability rises with the time at risk. The causal impacts of ALMP are assessed by comparing the outcomes for the group of participants in the treatment and the non-treatment worlds, see Column IV. They show that program participation increases the probability that a job search period ends with a job by approximately 2 percentage points. It also increases the level of participants' realized monthly earnings by around $640 \mathrm{NOK}$, or 2.5 percent. However, these favorable effects come at the cost of an increase in expected unemployment duration (including the participation period) of around 1.2 months, or around 9 percent.

In order to compare program benefits with program costs over a longer period of time, we simulate the progression of unemployment and employment spells for a full five-year period after entry into unemployment. Repeat spells start endogenously whenever a job termination is simulated. Individuals making transitions to education or other benefits are allowed to return to unemployment later on according to drawings from lotteries based on observed return-frequencies. A simple measure of the overall program effect is obtained by adding up all earnings generated from ordinary employment in the treatment and no-treatment worlds, respectively. This exercise indicates that over a five-year period, the adverse treatment effects (longer unemployment durations) dominate the favorable effects (higher employment and higher monthly earnings). However, some ALMP's clearly involve work of direct economic value. Around 60 percent of the program activities are employment programs in which presumably useful work is carried out, and the economic value of this work should be included in a cost-benefit evaluation; see Jespersen et al. (2008). It is of course difficult to assess this value, but since the program provider does not face the total wage cost, it is probably well below the participants' full earnings potentials. Job subsidies to private sector jobs are typically limited to a maximum of 50 percent of the wage bill, suggesting that the value of the work is likely to exceed 50 percent of actual earnings for these jobs. For work training schemes, the subsidy may be as high as 100 percent. The calculations provided in Table 8 are based on the assumption that subsidized work on average is worth 50 percent of the earnings level predicted for non-subsidized work. ALMP also involves administrative costs. Cost assessments made by the Public Employment Service (PES) suggest that the mean cost of providing ALMP in Norway - excluding all transfers to the participant - amounts to 3,620 NOK per 
month. ${ }^{8}$ Taking both the value of work within programs and the administrative costs of providing them into account, a simple comparison of costs and benefits during a five year period (upon entering unemployment) suggests that the programs are cost-effective. However, this conclusion is highly sensitive towards the valuation of work carried out within employment programs. For the cost-benefit analysis to yield a positive result, this value must on average exceed around 35 percent of expected earnings in non-subsidized jobs.

\subsection{The role of human capital, economic incentives and family situation}

The job seeker's human capital is of great importance, both with respect to the duration and outcome of the unemployment spell and with respect to job quality. Higher education and more work experience (conditional on age) imply shorter unemployment and higher probability of getting a job, and also higher earnings and more secure employment given that a job is found. Comparing, for example, a PhD education with a 12 year secondary education, the job hazard is approximately 40 percent higher, the earnings level is 42 percent higher, and the employment termination hazard is 47 percent lower, ceteris paribus.

It is difficult to evaluate the impacts of economic incentives embedded in the level of UI payments, since the benefit variation in our data is non-random. The estimated UI benefit elasticity in the employment hazard is -0.039 (0.001) (standard error in parenthesis). In the earnings equation, the elasticity is estimated to the negligible level of -0.004 (0.0005). However, the former of these estimates is much smaller than previously found on similar data with exploitation of random-assignment-like variation in UI benefits (Røed and Zhang, 2003; 2005); hence we view our results at this point with suspicion.

We also investigate the impact of the realized earnings level - i.e. the draw from the individual log-normal earnings distribution - on the employment termination process. The elasticity of the employment termination hazard with respect to the earnings level is estimated to 0.254 (0.016), i.e., a 10 percent increase in monthly earnings implies a 2.5 percent increase in the job termination hazard. This relationship is most likely driven by involuntary job terminations, and indicates that higher earnings (conditional on human capital variables) to some extent compensate for insecure jobs.

We have found that family situation - in terms of the number and age of children - has a substantial impact on the behavior of women, but virtually no impact on the behavior of

\footnotetext{
${ }^{8}$ The average monthly operating cost is stipulated to 662 NOK for work training and 8,208 for classroom training. Work training amount to 60.8 percent of all programs in our data window which makes the average cost $662 * 0.608+8208 * 0.392=3,620$ NOK per month.
} 
men. For women without children, we find that the job hazard rate is almost identical to that of otherwise identical men. However, upon obtaining a job, men’s earnings are approximately 17 percent higher than women's earnings, ceteris paribus. Having responsibility for small children reduces the women's job hazards and earnings substantially. For example, a having a single child aged 4-6 reduces the female job hazard by 41 percent and the expected earnings level by 12 percent.

\subsection{Unobserved heterogeneity}

The correlation structure of the six random individual effects is described in Table 9. We report rank correlation (Kendall's $\tau$ ) to avoid the excess influence that low-probability extreme (and imprecisely estimated) locations would have on standard correlation measures. ${ }^{9}$ There seems to be a positive unobserved selection into ALMP in the sense that the treatment propensity correlates positively with employment propensity. This is somewhat surprising, given the strong negative selection on observed variables. Our finding suggest that while ALMP participants are negatively selected with respect to key human capital variables such as education and work experience, they are positively selected on more intangible factors such as “spirit” and motivation (conditional on observed human capital). As expected, the unobserved employment propensity also correlates positively with earnings and negatively with the employment termination propensity.

\begin{tabular}{|c|c|c|c|c|c|}
\hline \multicolumn{6}{|c|}{$\begin{array}{l}\text { Table } 9 \\
\text { Unobserved heterogeneity - Rank correlation (Kendall's } \tau \text { ) }\end{array}$} \\
\hline & Education & Other benefits & ALMP & $\begin{array}{l}\text { Employment } \\
\text { termination }\end{array}$ & Log earnings \\
\hline Employment & -0.043 & -0.066 & 0.323 & -0.102 & 0.315 \\
\hline Education & - & 0.227 & 0.404 & 0.256 & -0.124 \\
\hline Other benefits & & - & 0.025 & 0.546 & -0.250 \\
\hline ALMP & & & - & 0.008 & 0.197 \\
\hline Employment termination & & & & - & -0.244 \\
\hline
\end{tabular}

Unobserved heterogeneity also explains a substantial fraction of earnings dispersion across individuals. From Table 2, we have that the overall standard deviation of log earnings is 0.602. By including observed covariates in a log-normal earnings regression, the standard

\footnotetext{
${ }^{9}$ Kendall's $\tau$ is computed on the basis of all possible pairs of individuals $(i, j)$ that can be formed on the basis of the estimated heterogeneity distribution. A pair $\left\{\left(v_{k i}, v_{l i}\right),\left(v_{k j}, v_{l j}\right)\right\}$ said to be concordant with respect to variables $(k, l)$ if $\left(v_{k i}-v_{k j}\right)\left(v_{l i}-v_{l j}\right)>0$ and discordant if $\left(v_{k i}-v_{k j}\right)\left(v_{l i}-v_{l j}\right)<0$. Let $c_{k l}$ be the number of concordant pairs and let $d_{k l}$ be the number of discordant pairs. We then compute Kendall's $\tau$ as $\tau_{k l}=\frac{c-d}{c+d}$. Note that we disregard the fraction $\sum_{s=1}^{Q} q_{s}^{2}$ of identical pairs drawn from the same location vector.
} 
deviation is reduced to 0.539 (not shown). Through the inclusion of unobserved heterogeneity, the estimated standard deviation in the person-specific log earnings distribution is further reduced to 0.386 (not shown). This nevertheless implies that each individual is subject to substantial earnings variability.

\section{Alternative model specifications and robustness}

We have estimated a number of alternative models, both to test particular hypothesis of economic interest and to assess the robustness of our results. In this section we briefly describe these alternative models and the corresponding estimation results. Complete results from all the estimations described in this section can be downloaded from our web site www.frisch.uio.no/docs/job_search.html.

\subsection{Liquidity constraints}

Existing empirical evidence indicates that the behavioral impacts of UI insurance depend on the prevalence of liquidity constraints (Chetty, 2008). For a large fraction of unemployment entrants in our dataset (those entering after 1994), we have register-based information on their own, as well as their family members', bank accounts at the end of the year prior to the year of entry into unemployment. We define liquidity as the sum of the family account balances divided by the square root of the number of family members. We then divide the analysis population in two equally sized groups; those with liquidity above the median and those with liquidity below the median. We estimate a version of the model described in Section 3 where all incentive and duration dependence parameters are allowed to vary between these two groups. The most important differences between the two groups are; first, that the transition rate to other benefits is significantly higher for job seekers with poor liquidity; second, that liquidity-constrained individuals exhibit stronger negative duration dependence in the hazard rate to employment; and third, that these individuals also lose a subsequent job much faster than non-constrained individuals. These findings may reflect that poor liquidity actually results from weak labor market attachment in the past, which is also associated with rapid discouragement and high exit probability through other benefits. We find no evidence that job seekers with poor liquidity responded particularly strongly to UI exhaustion or to the UI reform in 1997. 


\subsection{Non-modeled re-entries}

As explained in Section 3, re-entries into unemployment (repeat spells) are endogenously modeled insofar as they follow from the termination of an observed employment spell. However, the data also include a number of non-modeled re-entries into unemployment, namely those occurring after transitions to education or sickness/disability. These re-entries are thus treated as determined outside the model (exogenous). Since the process of re-entry may be driven by the same unobserved characteristics that determine modeled outcomes, this represent a potential source of sorting bias. To assess the importance of this problem we also estimate the model without including non-modeled re-entry spells. It turns out that while the inclusion of these spells does have some impact on the estimated effects of past unemployment (lagged duration dependence) it only has minor impacts on the parameters discussed in this paper.

\subsection{Part-time work}

UI claimants are obliged to report any part-time or occasional work that they perform while claiming benefits. If the earnings are $\mathrm{X}$ percent of previous full-time earnings, the benefit for the corresponding period is also reduced by $\mathrm{X}$ percent. These part-time work spells are recorded in the data, and in one version of the model we have included transitions to part-time work as an additional endogenous event (in exactly the same fashion as we include ALMP; see Section 3). The results from this exercise indicate that part-time and occasional work may serve as important stepping-stones towards more satisfactory employment. Otherwise, the results are very similar to those reported in Section 4. The reason why we left part-time work out of our preferred model is that we suspect measurement errors to be large. In particular, we do not systematically record part-time work for non-claimants. We also suspect that part-time work sometimes indicates that a satisfactory job is really found, but that it for some reason is difficult to start working full-time immediately (in which case our stepping-stone effect will be biased upwards).

\subsection{Unobserved heterogeneity}

While our preferred model is obtained on the basis of an AIC criterion (resulting in a joint discrete distribution of unobserved heterogeneity with 27 support points), we have of course also estimated the model with fewer support points, including only one (no unobserved heterogeneity). The results from the latter model are reported in full on our web page. Unsurprisingly, these results are significantly different from those reported in the paper, particularly 
with respect to the various duration dependence baselines. The "approach" towards the preferred model is smooth, however, and most of the estimated parameters are close to their "final” values after the inclusion of 10-15 points in the heterogeneity distribution. We also continued to include more points in the heterogeneity distribution after the AIC criterion was satisfied. However, apart from the heterogeneity parameters themselves (locations and probabilities), no parameters were visibly affected by this model extension. We terminated our likelihood improvement attempts after 35 support points.

\section{Conclusion}

An important feature of the UI system is the maximum duration by which job seekers are allowed to claim benefits without being forced into some form of activity. We have found that the determination of this parameter involves a number of tradeoffs. It is clearly the case that the longer benefits can be claimed without activity requirements, the higher the reservation wage and longer the time a typical job seeker uses to find a job. However, this is not only waste of time. Job search turns out to be a productive activity, and expected earnings derived from the first job match increase with as much as 13 percent during the first half year of job search. Moreover, generous job search conditions imply that fewer job search spells are terminated without a job being found at all. Fastidiousness declines significantly during the months just prior to UI exhaustion. This is mirrored in a 50 percent rise in the job hazard as well as in a 10 percent decline in the level of accepted earnings, ceteris paribus.

Actual participation in labor market programs also involves some conflicting mechanisms. There is initially an adverse unemployment lock-in effect that needs to be traded off against the apparently favorable human capital effects that come into play when the program has lasted for some time and/or is completed. On average, our findings suggest that program participation causes a 1.2 month increase in overall unemployment duration (including the participation period). However, it also causes a 2 percentage point increase in the probability that the unemployment spell eventually ends with a job. Program participation also tends to improve the quality of the job match. On average, program participation yields an initial earnings bonus of around 2.5 percent. Nevertheless, in terms of total earnings generated during the five year period after entry into unemployment, we find that the adverse unemployment duration effect dominates the favorable employment and earnings effects. In addition, programs are costly to administer. Hence, if we consider the time spent in program as being without economic value other than through the earnings it potentially generates later on, a cost-benefit calculation is bound to conclude that the programs are not worth their price. However, many 
programs (around 60 percent) involve some form of subsidized employment. If we assume that subsidized work has an economic value of at least 35 percent of non-subsidized work and abstract from general equilibrium effects, the cost-benefit analysis over a five-year period comes out with a favorable conclusion.

We conclude that in order to justify the high level of labor market program activity in Norway one cannot focus exclusively on programs as a means to promote the participants' human capital and later employment careers. The most important benefits of ALMP's actually seem to come from two other sources. First, they offset the moral hazard problems embedded in unemployment insurance systems. Activity requirements effectively reduce the leisure associated with being a UI claimant and, hence, encourages active job search and discourages excessive "choosiness". Although we have shown i this paper that the latter of these effects implies a reduction in the level of accepted earnings from the first job, a quick entry into ordinary employment may provide a stepping stone towards better paid jobs. Second, active programs represent an alternative way of exploiting the "waiting time” until an ordinary job can be found. Many program participants contribute directly to the production of valuable goods and services, and a short increase in overall unemployment duration (including the participation period) may be considered a price worth paying for this benefit.

\section{References}

Abbring, J. H. and Van den Berg, G. J. (2003) The Non-Parametric Identification of Treatment Effects in Duration Models. Econometrica, Vol. 71, No. 5 (September), 14911517.

Acemoglu, D. and Shimer, R. (1999) Efficient Unemployment Insurance. The Journal of Political Economy, Vol. 107, 893-928.

Acemoglu, D. and Shimer, R. (2000) Productivity gains from unemployment insurance. European Economic Review, Vol. 44, 1195-1224.

Addison, J. T. and Blackburn, M. L. (2000) The Effects of Unemployment Insurance on Post-unemployment Earnings. Labor Economics, Vol. 7, 21-53.

Belzil, C. (2001) Unemployment Insurance and Subsequent Job Duration: Job Matching versus Unobserved Heterogeneity. Journal of Applied Econometrics, Vol. 16, 619-636.

Black, D. A., Smith, J. A, Berger, M. C. and Noel, B. J. (2003) Is the Threat of Reemployment Services More Effective than the Services Themselves? Evidence from Random Assignment in the UI System. American Economic Review, Vol. 93, 1313-1327. 
Brinch, C. (2007) Non-Parametric Identification of the Mixed Hazards Model with Time Varying Covariates. Econometric Theory, Vol. 23, 349-354.

Card, D., Chetty, R. and Weber, A. (2007) The Spike at Benefit Exhaustion: Leaving the Unemployment System or Starting a New Job? American Economic Review, Vol. 97, No. 2 (PAP), 113-118.

Centeno, M. (2004) The Match Quality Gains from Unemployment Insurance. Journal of Human Resources, Vol. 39, No. 3, 839-863.

Chetty, R. (2008) Moral Hazard versus Liquidity and Optimal Unemployment Insurance. Journal of Political Economy, Vol. 116, No.2, 173-234.

Eberwein, C., Ham, J. C. and LaLonde, R. J. (1997). The Impact of Being Offered and Receiving Classroom Training on the Employment Histories of Disadvantaged Women: Evidence from Experimental Data. Review of Economic Studies, Vol. 64, 655-82.

Gaure, S. and Røed, K. (2007) How Tight is the Labour Market? Sources of Changes in the Aggregate Exit Rate from Unemployment across the Business Cycle. Journal of Business Cycle Measurement and Analysis, Vol. 3, No. 2, 155-174.

Gaure, S., Røed, K. and Zhang, T. (2007) Time and Causality: A Monte Carlo Assessment of the Timing-of-Events Approach. Journal of Econometrics, Vol. 141 (2007) 11591195.

Heckman, J. and Singer, B. (1984) A Method for Minimizing the Impact of Distributional Assumptions in Econometric Models for Duration Data. Econometrica, Vol. 52, 271320.

Jespersen, S. T., Munch, J. R, and Skipper, L. (2008) Costs and Benefits of Danish Active Labour Market Programmes. Labour Economics, forthcoming.

Kluve, J., Card, D. and Fertig, M. (2007) Active Labor Market Policies in Europe - Performance and Perspectives. Springer-Verlag Berlin and Heidelberg GmbH \& Co.

Lindsay, B. G. (1983) The Geometry of Mixture Likelihoods: A General Theory. The Annals of Statistics, Vol. 11, 86-94.

Marimon, R. and Zilibotti, F. (1999) Unemployment vs. Mismatch of Talents: Reconsidering Unemployment Benefits. The Economic Journal, Vol. 109, 266-291.

McCall, B. P. (1994) Identifying State Dependence in Duration Models. American Statistical Association 1994, Proceedings of the Business and Economics Section, 14-17.

Meyer, B. D. (1990) Unemployment Insurance and Unemployment Spells. Econometrica, Vol. 58, No. 4, 757-782. 
Prentice, R. L. and Gloeckler, L. A. (1978) Regression Analysis of Grouped Survival Data with Application to Breast Cancer Data. Biometrics, Vol. 34, 57-67.

Røed, K. and Raaum, O. (2006) Do Labour Market Programmes Speed up the Return to Work? Oxford Bulletin of Economics and Statistics, Vol. 68, No. 5, 541-568.

Røed, K. and Westlie, L. (2007) Unemployment Insurance in Welfare States: Soft Constraints and Mild Sanctions. IZA Discussion Paper No. 2877.

Røed, K. and Zhang, T. (2003) Does Unemployment Compensation Affect Unemployment Duration? The Economic Journal, Vol. 113, 190-206.

Røed, K. and Zhang, T. (2005) Unemployment Duration and Economic Incentives - A Quasi Random-Assignment Approach. European Economic Review, Vol. 49, 1799-1825.

Van Ours, J. C. and Vodopivec, M. (2008) Does Reducing Unemployment Insurance Generosity Reduce Job Match Quality? Journal of Public Economics, Vol. 92, No.3-4, 684695. 